\title{
Escherichia coli Glucuronylsynthase: An Engineered Enzyme for the Synthesis of $\beta$-Glucuronides
}

2008

Vol. 10, No. 8

1585-1588

\author{
Shane M. Wilkinson, ${ }^{\dagger}$ Chu W. Liew, ${ }^{\ddagger}$ Joel P. Mackay, ${ }^{\ddagger}$ Hamzah M. Salleh,,,,$l$ \\ Stephen G. Withers,,$^{\S}$ and Malcolm D. McLeod ${ }^{\star}, \dagger$
}

School of Chemistry, University of Sydney, NSW 2006, Australia, School of Molecular and Microbial Biosciences, University of Sydney, NSW 2006, Australia, and

Department of Chemistry, University of British Columbia, Vancouver,

BC V6T 1Z1, Canada

m.mcleod@rsc.anu.edu.au

Received February 6, 2008

\section{ABSTRACT}

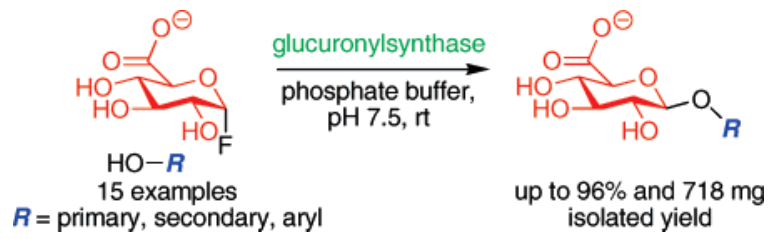

The glycosynthase derived from $E$. coli $\beta$-glucuronidase catalyzes the glucuronylation of a range of primary, secondary, and aryl alcohols with moderate to excellent yields. The procedure provides an efficient, stereoselective, and scalable single-step synthesis of $\beta$-glucuronides under mild conditions.

The formation of glucuronide conjugates during phase II metabolism is a major pathway for the elimination of xenobiotic and some endobiotic compounds from the body. ${ }^{1}$ The identification, quantification, and pharmacological evaluation of these metabolites is essential in many fields including sports drug testing, ${ }^{2}$ the detection of agricultural residues, ${ }^{3}$ and drug development, ${ }^{1}$ leading to a significant demand for glucuronide standards.

† School of Chemistry, University of Sydney. Current address: Research School of Chemistry, Australian National University, Canberra, ACT 0200, Australia.

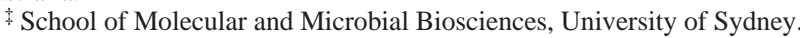

$\S$ University of British Columbia.

" Current address: Department of Biotechnology Engineering, International Islamic University Malaysia, Kuala Lumpur, 53100, Malaysia.

(1) (a) Shipkova, M.; Wieland, E. Clin. Chim. Acta 2005, 358, 2. (b) Wells, P. G.; Mackenzie, P. I.; Chowdhury, J. R.; Guillemette, C.; Gregory, P. A.; Ishii, Y.; Hansen, A. J.; Kessler, F. K.; Kim, P. M.; Chowdhury, N. R.; Ritter, J. K. Drug Metab. Dispos. 2004, 32, 281.

(2) Schänzer, W.; Donike, M. Anal. Chim. Acta 1993, 275, 23.

(3) (a) Kim, H.-J.; Ahn, K. C.; Ma, S. J.; Gee, S. J.; Hammock, B. D. J. Agric. Food Chem. 2007, 55, 3750. (b) Hebestreit, M.; Flenker, U.; Buisson, C.; Andre, F.; Le Bizec, B.; Fry, H.; Lang, M.; Weigert, A. P.; Heinrich, K.; Hird, S.; Schanzer, W. J. Agric. Food Chem. 2006, 54, 2850.
The preparation of glucuronides presents significant challenges for existing methods of glucuronylation. ${ }^{4}$ Chemical methods ${ }^{5}$ of glucuronylation are based on the KoenigsKnorr reaction or related procedures but often suffer from poor yields and side reactions due to the low reactivity of glucuronic acid derived glycosyl donors ${ }^{4,5}$ and require one or more deprotection steps to liberate free glucuronide. Enzymatic methods ${ }^{6}$ of synthesis employ uridine $5^{\prime}$-diphosphoglucuronosyl transferases (UGTs): a superfamily of

(4) (a) Kaspersen, F. M.; Van Boeckel, C. A. A. Xenobiotica 1987, 17, 1451. (b) Stachulski, A. V.; Jenkins, G. N. Nat. Prod. Rep. 1998, 15, 173. (c) Stachulski, A. V.; Harding, J. R.; Lindon, J. C.; Maggs, J. L.; Park, B. K.; Wilson, I. D. J. Med. Chem. 2006, 49, 6931.

(5) For recent chemical synthesis, see: (a) Engstrom, K. M.; Daanen, J. F.; Wagaw, S.; Stewart, A. O. J. Org. Chem. 2006, 71, 8378. (b) Harding, J. R.; King, C. D.; Perrie, J. A.; Sinnott, D.; Stachulski, A. V. Org. Biomol. Chem. 2005, 3, 1501. (c) Poláková, M.; Pitt, N.; Tosin, M.; Murphy, P. V. Angew. Chem., Int. Ed. 2004, 43, 2518.

(6) For recent enzymic synthesis, see: (a) Jäntti, S. E.; Kiriazis, A.; Reinilä, R. R.; Kostiainen, R. K.; Ketola, R. A. Steroids 2007, 72, 287. (b) Khymenets, O.; Joglar, J.; Clapés, P.; Parella, T.; Covas, M.-I.; de la Torre, R. Adv. Synth. Catal. 2006, 348, 2155. (c) Kuuranne, T.; Aitio, O.; Vahermo, M.; Elovaara, E.; Kostiainen, R. Bioconjugate Chem. 2002, 13, 194. 
enzymes responsible for glucuronylation in the body.,8 This procedure provides a mild and stereospecific synthesis in a single step. However, UGTs are substrate-specific to the acceptor alcohol and practical considerations often limit this procedure to small scale syntheses. Given the limitations associated with existing methods, the development of improved glucuronylation protocols is an important goal.

Escherichia coli $\beta$-glucuronidase (EC 3.2.1.31) is a member of the retaining $\beta$-glycosidase family 2 and catalyzes the hydrolytic cleavage of terminal $\beta$-glucuronide residues. The enzyme has found application in the field of analytical chemistry for the deconjugation of a broad range of glucuronide metabolites. The enzyme active site contains two key catalytic residues. The side chain of glutamic acid 504 $(\mathrm{E} 504)^{9}$ acts as a nucleophile, and glutamic acid 413 (E413) is responsible for general acid/base catalysis in a doubledisplacement mechanism (Scheme 1a). As demonstrated for

Scheme 1. Proposed Mechanism of Action of (a) E. coli WT $\beta$-Glucuronidase and (b) the E. coli $\mathrm{E} 504 \mathrm{G}$ $\beta$-Glucuronylsynthase

a)
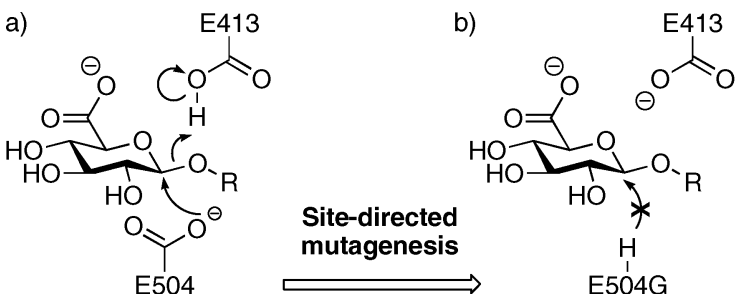

$\mathrm{H}_{2} \mathrm{O}$

ROH

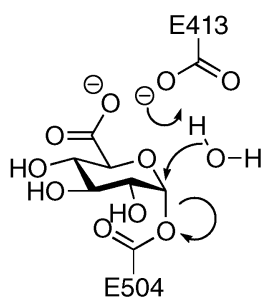

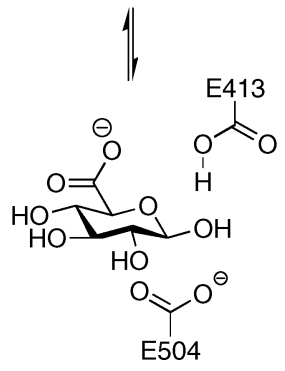

E504

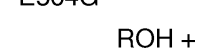

$\alpha$-D-glucuronyl

- $\beta$-D-glucuronide
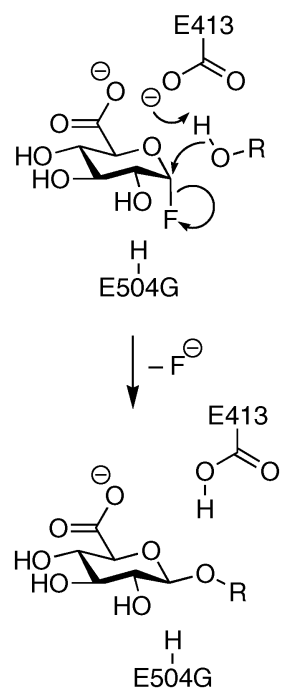

a range of other retaining $\beta$-glycosidase enzymes, ${ }^{10,11}$ mutation of E504 to a non-nucleophilic glycine (E504G), alanine

(7) Mulder, G. J. Annu. Rev. Pharmacol. Toxicol. 1992, 32, 25.

(8) Werschkun, B.; Wendt, A.; Thiem, J. J. Chem. Soc., Perkin Trans. 1 1998, 3021.

(9) Wong, A. W.; He, S.; Withers, S. G. Can. J. Chem. 2001, 79, 510.

(10) Mackenzie, L. F.; Wang, Q.; Warren, R. A. J.; Withers, S. G. J. Am. Chem. Soc. 1998, 120, 5583.

(E504A), or serine (E504S) residue disables the hydrolytic pathway (Scheme 1b). However, the resulting glycosynthase enzyme can catalyze the formation of glucuronide product from $\alpha$-D-glucuronyl fluoride (1) and an acceptor alcohol substrate. In this paper, we report the development of a conceptually distinct approach, based on the glycosynthase $\mathrm{e}^{10,11}$ derived from $E$. coli $\beta$-glucuronidase, for the mild, singlestep synthesis of glucuronides that is liberated from the many drawbacks associated with contemporary procedures.

The E504G, E504A, and E504S glucuronylsynthase mutants were created using standard overlap mutagenesis, subcloned into the pET28a $(+)$ expression vector and transformed into a $\beta$-glucuronidase-deficient strain of $E$. coli (GMS407(DE3)). The wild-type (WT) E. coli $\beta$-glucuronidase was also expressed in the same manner.

The aglycon specificity of $E$. coli glucuronidase and of the putative glycosynthase enzymes was determined using an established spectrophotometric screening protocol. ${ }^{12,13}$ This screen employs WT $\beta$-glucuronidase inactivated with 2-deoxy-2-fluoro- $\beta$-D-glucuronyl fluoride. ${ }^{14}$ A panel of 123 alcohol acceptors was evaluated in parallel for their ability to reactivate this inactivated enzyme by glucuronyl transfer (Scheme 2). ${ }^{12}$ Surprisingly, of the 54 carbohydrate

Scheme 2. Acceptor Screening by Reactivation of Inactivated E. coli WT $\beta$-Glucuronidase Enzyme

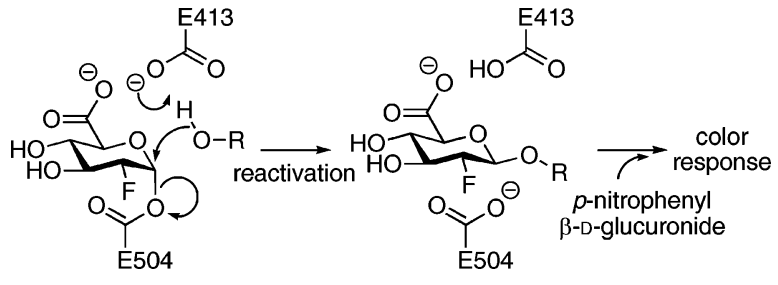

acceptors screened, none gave significant reactivation of the inactivated enzyme relative to control. In contrast, thirteen of the 69 alcohol acceptors screened significantly enhanced reactivation rates $(2-8 \times$ control). The thirteen alcohols identified by this screen included a range of primary and cyclic secondary aliphatic alcohols, substituted benzyl alcohols, and isomeric naphthalene methanols (Table $1, \mathbf{2} \mathbf{a}-\mathbf{m})$. The screening suggested an unusual preference for non-carbohydrate based acceptors to occupy the aglycon binding site of WT $\beta$-glucuronidase and glycosynthase enzymes.

Microgram scale reactions to identify glycosynthase activity were performed with the 13 alcohols $(\mathbf{2} \mathbf{a}-\mathbf{m}), \alpha$-Dglucuronyl fluoride $\mathbf{1},{ }^{15}$ and the three potential glucuronyl-

(11) For a review on glycosynthases, see: Williams, S. J.; Withers, S. G. Aust. J. Chem. 2002, 55, 3.

(12) Blanchard, J. E.; Withers, S. G. Chem. Biol. 2001, 8, 627.

(13) The details of the screening protocol and the full list of alcohols used in the screen is reported in the Supporting Information.

(14) Wong, A. W.; He, S.; Grubb, J. H.; Sly, W. S.; Withers, S. G. J. Biol. Chem. 1998, 273, 34057.

(15) Prepared by TEMPO-mediated oxidation of $\alpha$-D-glucopyranosyl fluoride. Synthetic procedures and spectroscopic data are reported in the Supporting Information. 
Table 1. E. coli Glucuronylsynthase-Catalyzed Glucuronylation

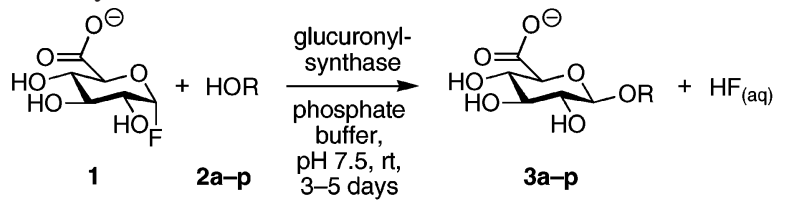

yield of $3(\%)^{b}$
entry $^{a}$

${ }^{a}$ Reactions were performed using $\alpha$-D-glucuronyl fluoride 1 (1.1-1.2 equiv), E504G glucuronylsynthase $\left(0.1 \mathrm{mg} \mathrm{mL}^{1}\right)$ in $50 \mathrm{mM}$ sodium phosphate buffer, $\mathrm{pH} 7.5$ unless otherwise stated. ${ }^{b}$ Yield in parentheses denotes the yield obtained from the alanine glucuronylsynthase (E504A). ${ }^{c} 12.5 \% \mathrm{v} / \mathrm{v} .{ }^{d} 25 \% \mathrm{v} / \mathrm{v} .{ }^{e}$ Reaction performed on a $2.5 \mathrm{mmol}$ scale. ${ }^{f} 2 \%$ w/v. ${ }^{g} 0.5 \% \mathrm{w} / \mathrm{v} .{ }^{h} 1 \% \mathrm{w} / \mathrm{v} .{ }^{i}$ Saturated acceptor $\left(1.4 \mathrm{mg} \mathrm{mL}^{-1}\right)$, E504G $(0.2$ $\left.\mathrm{mg} \mathrm{mL}{ }^{-1}\right)$, and $100 \mathrm{mM}$ sodium phosphate buffer, $\mathrm{pH} 7.5$ was used. ${ }^{j} 2.5 \%$ $\mathrm{w} / \mathrm{v}$.

synthase enzymes (E504A, E504G, and E504S). Glucuronide products $\mathbf{3 a}-\mathbf{m}$ were identified by ESI-MS for all 13 alcohols in the presence of the glycine (E504G) and alanine (E504A) mutants. No product formation was observed in the absence of enzyme or for the serine mutant (E504S), which was not examined further.

To explore the synthetic potential of the glycosynthase enzymes, reactions involving the 13 alcohol acceptors $(\mathbf{2 a}-\mathbf{m})$ were performed on a preparative scale $(5-10 \mathrm{mg})$ in the presence of the E504G or E504A glucuronylsynthase mutants. The E504G mutant cleanly afforded the $\beta$-glucuronide products $\mathbf{3 a}-\mathbf{m}$ in $37-93 \%$ isolated yield (Table 1, entries a-m), with the E504A mutant affording lower yields in the cases examined (entries $\mathrm{i}$ and $\mathrm{m}$ ). The low aqueous solubility of a number of acceptor alcohols was overcome in two ways. Dimethyl sulfoxide (DMSO) was used as cosolvent in concentrations of up to $25 \% \mathrm{v} / \mathrm{v}$ (entries b-e, $\mathrm{h}, \mathrm{j}, \mathrm{l}, \mathrm{m}$ ), with the enzyme retaining useful activity at these levels. The nonionic detergent, $n$-dodecyl $\beta$-maltoside (DDM), was also found to be effective at low concentrations resulting in improved yields (entries $\mathrm{j}, \mathrm{k}, \mathrm{m}$ ). No oligomer formation was detected in these reactions, consistent with the observation that carbohydrates do not serve as efficient acceptors in the screen of aglycon specificity. The glucuronylation of phenylethanol $\mathbf{2 f}$ on a large scale afforded the desired glucuronide $3 \mathbf{f}$ in $96 \%$ yield $(718 \mathrm{mg})$.

The synthesis reaction was also attempted with ethanol and phenol; two potential acceptors that formed part of the screen but that were not identified as hits. Indeed, ethanol failed to afford the glucuronide product (entry $\mathrm{n}$ ), while a small quantity of phenyl $\beta$-D-glucuronide (3m) was isolated in $13 \%$ yield (entry o) using the E504G glucuronylsynthase. The low yield of this reaction can be rationalized by the poor nucleophilicity of phenol but also hints at a broader substrate scope for the glycosynthase mutants.

To further demonstrate the scope of the engineered glycosynthase enzyme, the reaction was performed on the steroid hormone dehydroepiandrosterone (DHEA, 2p). This substrate was only partially soluble in $25 \%$ DMSO or $2.5 \%$ DDM solutions, so the reaction was performed with the steroid as a suspension (Table 1, entry p). The glucuronide (3p) was obtained in 5\% yield in the absence of additives, 17\% yield using DMSO and 26\% using DDM with $73 \%$ recovery of residual starting material. Although of modest yield, these results illustrate the promise of the glucuronylsynthase enzyme for the synthesis of a range of important glucuronide products on a scale sufficient for modern analytical methods.

This glucuronylsynthase, the latest addition to the glycosynthase range, has been shown to catalyze the glucuronylation of a range of alcohols with moderate to excellent yields. This new procedure provides an efficient, stereoselective, and scalable single-step synthesis of $\beta$-glucuronides under mild conditions. It is envisaged that this alternative method of synthesis will assist to meet the demand for glucuronide standards required for analytical purposes. Further engineering will be directed to increasing the substrate scope and improving the catalytic efficiency of the glucuronylsynthase enzyme.

Acknowledgment. Dr. Kelvin Picker, School of Chemistry, University of Sydney, is acknowledged for assistance 
with affinity chromatography and MS. We thank the University of Sydney and the Natural Sciences and Engineering Council of Canada for financial support.

Supporting Information Available: Protein expression procedures, experimental procedures, spectroscopic data and
${ }^{1} \mathrm{H}$ and ${ }^{13} \mathrm{C}$ NMR spectra for compounds $\mathbf{1}$ and $\mathbf{3 a}-\mathbf{p}$. This material is available free of charge via the Internet at http://pubs.acs.org.

OL8002767 